Please do not remove this page

RMIT

UNIVERSITY

\title{
A discriminative analysis of approaches to ranking fuzzy numbers in fuzzy decision making
}

Deng, Hepu

https://researchrepository.rmit.edu.au/esploro/outputs/9921863089201341/filesAndLinks?institution=61RMIT_INST\&index=null

Deng, H. (2007). A discriminative analysis of approaches to ranking fuzzy numbers in fuzzy decision making. Proceedings of the Fourth IEEE International Conference on Fuzzy Systems and Knowledge Discovery, 22-27. https://doi.org/10.1109/FSKD.2007.20

Published Version: https://doi.org/10.1109/FSKD.2007.20

Repository homepage: https://researchrepository.rmit.edu.au

(c) 2007 IEEE. Personal use of this material is permitted. However, permission to reprint/republish this material for advertising or promotional purposes or for creating new collective works for resale or redistribution to servers or lists, or to reuse any copyrighted component of this work in other works must be obtained from the IEEE.

Downloaded On 2023/04/26 14:01:21 +1000 


\title{
A Discriminative Analysis of Approaches to Ranking Fuzzy Numbers in Fuzzy Decision Making
}

\author{
Hepu Deng \\ School of Business Information Technology, RMIT University \\ GPO Box 2476VMelbourne, Victoria, 3000, Australia \\ Email: hepu.deng@rmit.edu.au
}

\begin{abstract}
This paper presents a discriminative analysis of approaches to ranking fuzzy numbers in fuzzy decision making based on a comprehensive review of existing approaches. The consistency and effectiveness of the approaches to ranking fuzzy numbers are examined in terms of two objective measures developed, leading to a better understanding of the relative performance of individual approaches in ranking fuzzy numbers. Representative fuzzy numbers are selected for carrying out the comparative study of several typical approaches in ranking fuzzy numbers. Several interesting findings are identified which may be of practical significance to fuzzy decision making in real situations.
\end{abstract}

\section{Introduction}

Comparing and ranking fuzzy numbers for determining their overall rankings are an important part of fuzzy decision making $[1,2,4,13]$. This is because these fuzzy numbers can be obtained in a fuzzy decision making situation to represent the overall utilities of decision alternatives, commonly referred to as fuzzy utilities $[1,2$, $8,13,14,18-24,39,68]$. Most fuzzy decision making approaches developed in the context of multi-attribute utility theory $[13,18,29]$ consist of the fuzzy utility aggregation process and the fuzzy utility comparison process. A comparison between fuzzy utilities (fuzzy numbers) thus is a comparison between decision alternatives $[2,18,36,49,62,68]$.

Numerous approaches have been developed for comparing and ranking fuzzy numbers. Freeling [27], Bortoland and Degani [5], Nakamura [46, 47], Lee and Li [38], Tseng et al. [53], Chen and Hwang [13], and Yeh and Deng [62] have conducted comprehensive reviews based on various classifications. In general all the ranking approaches produce sound ranking results for clear-cut problems [13, 68]. However, for problems where fuzzy numbers involved only differ slightly from each other, count-intuitive ranking outcomes may occur $[13,62,68]$. There is a lack of understanding of the relative performance of existing approaches, in particular with respect to the discrimination-ability of these approaches in differentiating similar fuzzy numbers which is often critical in real decision situations $[13,62]$.

This paper presents a discriminative analysis of approaches to ranking fuzzy numbers for decision making in a fuzzy environment. The consistency and effectiveness of these approaches in ranking fuzzy numbers are examined in terms of two objective measures developed, leading to a better understanding of the performance of individual approaches. Representative fuzzy numbers are selected for carrying out the discriminative study of several typical approaches in ranking fuzzy numbers. Several interesting findings are identified which may be of practical significance to fuzzy decision making.

\section{A review of ranking approaches}

The significance of ranking fuzzy numbers for solving real world decision problems in a fuzzy environment [67] leads to the tremendous efforts being spent on the development of various ranking approaches [13, 62]. These approaches can be categorized into mathematical approaches and linguistic approaches $[5,13]$.

Linguistic approaches focus on the development and use of linguistic terms for describing the ranking outcome which is not ordinal $[13,50,66,68]$. This study does not include linguistic approaches in the discriminative analysis study. Mathematical approaches consist of defining a ranking function for mapping a fuzzy number into a real one where a natural order exists [13], resulting in a single or multiple crisp index values $[13,68]$. This study aims to examine the consistency and effectiveness of mathematical approaches to ranking fuzzy numbers.

Depending on the way that the ranking index is derived, mathematical approaches can further be divided into (a) independent ranking approaches, (b) referenceoriented ranking approaches, and (c) pairwise comparison based ranking approaches. Table 1 shows an overview of the classification of fuzzy ranking approaches.

The independent ranking approaches are the most common approach involving the development of a mapping function to associate a fuzzy number with a positive real number. The ranking of fuzzy numbers is based on comparing their corresponding real values. Approaches of Adamo [1], Buckley and Chanas [6], 
Yager [58, 61], Chang [9], Murakami et al. [45], Lee and Li [38, 40], Campos and Munoz [7], and Liou and Wang [41] are in this category.

Table 1 A classification of fuzzy ranking approaches

\begin{tabular}{|c|c|}
\hline Characteristics & Ranking Approaches \\
\hline $\begin{array}{l}\text { Independent } \\
\text { Ranking }\end{array}$ & $\begin{array}{l}\text { Adamo [1], Yager [59, 61], Chang [9], } \\
\text { Murakami et al. [45], Lee and Li [38], } \\
\text { Campos and Munoz [7], Liou and Wang [41]. }\end{array}$ \\
\hline $\begin{array}{l}\text { Reference- } \\
\text { oriented } \\
\text { Ranking }\end{array}$ & $\begin{array}{l}\text { Yager [60,61], Jain [31,32], Kerre [34], Chen } \\
\text { [11], Kim and Park [35], Choobineh and Li } \\
\text { [15], .De Campos-Ibanez and Gonzalz-Munoz }\end{array}$ \\
\hline $\begin{array}{l}\text { Pairwise } \\
\text { Comparison } \\
\text { Ranking }\end{array}$ & $\begin{array}{l}\text { Bass and Kwakernaak [2], Baldwin and Guild } \\
\text { [3], Watson et al. [57], Nakamura [46, 47], } \\
\text { Kolodziejczyk [37], Tseng and Klein [52], } \\
\text { Yuan [63], Dubois and Prade [23], Tsukamoto } \\
\text { et al. [54], and Delgado et al. [17] }\end{array}$ \\
\hline $\begin{array}{l}\text { Linguistic } \\
\text { Ranking } \\
\end{array}$ & $\begin{array}{l}\text { Zadeh [64,65, 66], Freeling [27], Efstathiou } \\
\text { and Tong [25], Tong and Bonissone [51] }\end{array}$ \\
\hline
\end{tabular}

With the use of reference-oriented ranking approaches, reference fuzzy sets are usually defined for establishing a common base to compare the fuzzy numbers in question during the ranking process. Each fuzzy number is evaluated based on its closeness to the reference sets [10, $18,30,33,36,55,56,62]$ via specifically developed mathematical functions, usually taking the form as follows $\mu_{z_{i}}\left(z_{i}\right)=\mu_{Y}(y) * \mu_{A_{i}}\left(x_{i}\right)$ where $Y$ is a reference set, * denotes a given operator for defining the relationship between $Y$ and $A_{i}$, and $Z_{i}=\left\{\left(z_{i}, \mu_{Z_{i}}\left(z_{i}\right)\right)_{,} z_{i} \in R\right\}$ is the resultant fuzzy set for each $A_{i}$ to represent its relative ranking in relation to $Y$ [62]. Approaches of Yager [60], Jain [31, 32], Kerre [34], Chen [11], Kim and Park [35], Choobineh and Li [15], Chen and Lu [12], de CamposIbanez and Gonzalez-Munoz [16], and Yeh and Deng [62] are developed based on this concept. Approaches in this group usually require considerable computation, particularly when continuous membership functions are present. Counter-intuitive ranking outcomes may occur under some circumstances $[5,13,68]$.

Using pairwise comparison for determining the preference of alternatives is widely applied in fuzzy decision making. When all the pairwise comparison results are obtained, additional procedures can be developed to acquire a total order of alternatives. A typical application of this concept is the analytic hierarchy process $[18,48]$ based on the numerical scale of Miller [44]. Applying this concept to ranking fuzzy numbers has led to the development of several approaches, including those of Bass and Kwakernaak [2], Baldwin and Guild [3], Watson et al. [57], Tsukamoto et al. [54], Tseng and Klein [52], Nakamura [46, 47], Kolodziejczyk [37], Yuan [63], Dubois and Prade [23], and Delgado et al. [17]. These approaches usually involve in (a) constructing a fuzzy binary preference relation between two fuzzy numbers based on their pairwise comparison and (b) determining the final ranking of all fuzzy numbers based on the fuzzy binary preference relations $[13,68]$.

When only two fuzzy numbers are present in the ranking process, the ranking relation between these two fuzzy numbers can be usually formulated as $A_{1}>A_{2} \Leftrightarrow$ $\mathrm{P}\left(\mathrm{A}_{1}, \mathrm{~A}_{2}\right)>\mathrm{P}\left(\mathrm{A}_{2}, \mathrm{~A}_{1}\right), \mathrm{A}_{1}=\mathrm{A}_{2} \Leftrightarrow \mathrm{P}\left(\mathrm{A}_{1}, \mathrm{~A}_{2}\right)=\mathrm{P}\left(\mathrm{A}_{2}, \mathrm{~A}_{1}\right)$, and $A_{1}<A_{2} \Leftrightarrow P\left(A_{1}, A_{2}\right)<P\left(A_{2}, A_{1}\right)$ where the fuzzy binary relation $P\left(A_{i}, A_{j}\right)$ representing the degree of preference of fuzzy numbers $A_{i}$ to $A_{j}$ can be developed in different manners. There are, however, difficulties when more than two fuzzy numbers are involved, as these fuzzy binary preference relations do not always abide the property of transitivity $[13,68]$. In this situation, specific procedures are required for determining the overall ranking of fuzzy numbers during the ranking process.

Two ways are followed in the literature to address this problem for determining the total ranking order based on the available fuzzy binary preference relations. One is to use the min operator for aggregating the fuzzy binary relationships fro determining the overall crisp rankings, represented by the approaches of Bass and Kwakernaak [2] and Baldwin and Guild [3]. The other approach to ranking fuzzy numbers based on available fuzzy binary preference relations is to introduce a certain transitivity property into the construction of the fuzzy preference relation $P\left(A_{i}, A_{j}\right)$ in order to eliminate the inconsistency which leads to a conflicting order relation such as $A_{i}>A_{j}$, $A_{j}>A_{k}$, and $A_{k}>A_{i}$. Approaches of Nakamura [46, 47], Kolodziejczyk [37], Tseng and Klein [52], Yuan [63], Dubois and Prade [23], Tsukamoto et al. [54], and Delgado et al. [17] are in this category.

These approaches are complicated in calculating the index for each fuzzy number. The computation involved is tremendous, in particular when various forms of fuzzy numbers are present. In some situations, these indices may also produce counter-intuitive ranking outcomes [13, 62].

Individual approaches in ranking fuzzy numbers have their own merits. The performances of these approaches are very different as they are developed based on different principles. To facilitate their applications in decision making for addressing real world problem, it is obviously desirable to conduct a discriminate analysis of these approaches for a better understanding of their performance, in particular their discrimination ability in differentiating similar fuzzy numbers.

\section{Measures for discriminative analysis}

The importance of understanding the performance of existing ranking approaches for fuzzy decision making is obvious. Two objective measures, the ranking consistency measure and the ranking effectiveness measure, are developed for carrying out the discriminative analysis. These two measures can be used to help explore the 
performance of existing approaches which is useful for assisting the decision maker in selecting appropriate approaches for solving practical decision problems.

The ranking consistency measure aims to scrutinize the consistency of rankings of fuzzy numbers between each ranking approach and the intuitive ranking approach. It can be determined by comparing the ranking outcomes resulted from each ranking approach and the intuitive ranking approach, using Spearman's rank order correlation coefficient $[3,34,43]$, given as

$$
R C=1-\frac{\sum_{i=1}^{n}\left(g_{i}^{d}-g_{i}^{N}\right)^{2}}{n\left(n^{2}-1\right)}
$$

The ranking effectiveness measure is designed to evaluate the discrimination-ability of individual approaches in differentiating fuzzy numbers. This measure is used to describe the degree to which fuzzy numbers are distinguished, based on the ranking values of fuzzy numbers. The measure is based on the perception that the decision maker would have more confidence in selecting a decision alternative when its corresponding ranking value is much larger than those of other alternatives [62].

For a set of $n$ normalized ranking values $P_{i}(i=1,2, \ldots$, n) listed in descending preference order, the ranking effectiveness measure $\left(R E_{k} \in[0,1]\right)$ can be calculated as

$$
R E_{k}=\frac{\sum_{i=1}^{k} \frac{P_{i}-P_{i+1}}{\max \left(\frac{1}{k},\left(P_{i}-P_{i+1}\right)\right)}}{k}, k \in\{1,2, \ldots, n-1\},
$$

where $k$ is an integer indicating the number of alternatives the decision maker wants to select out of $n$ alternatives. $R E_{k}$ is measured by the average ratio of the difference between each pair of adjacent ranking values $P_{i}$ and $P_{i+1}$ and the ideal number of fuzzy numbers to be differentiated. For example, only the first $k$ ranking values requires the attention of the decision maker if he/she just wants to select the first $k$ alternatives associated with fuzzy numbers. The larger the value of the ranking effectiveness measure is, the better the discriminationability of the ranking approach is, and the more confident the decision maker is in making the selection decisions.

\section{A discriminative analysis}

A discriminative analysis is carried out in this section to evaluate the relative performance of several typical approaches to ranking fuzzy numbers. A few approaches such as Buckley and Chanas's index [6], Mabuchi's index [43], and the multi-indices approaches presented by Dubois and Prade [23], Tsukamoto et al. [54], and Delgado et al. [17] are not included due to the practical limitation and complexity of the index themselves. Representative fuzzy numbers as shown in Figure 1 are selected from Bortoland and Degani [5], Nakamura [46,
47], Lee and Li [38], Tseng et al. [53], Chen and Hwang [13], and Yeh and Deng [62].
$\mathrm{A}_{1}$

(A)

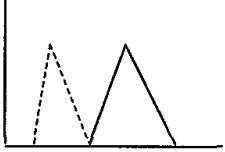

(C)

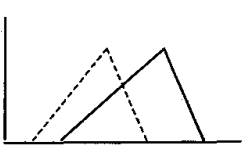

(E)

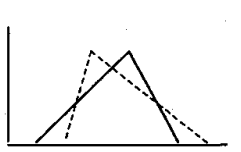

(G)

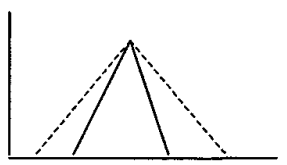

(I)

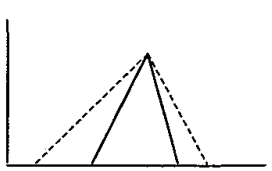

$\mathrm{A}_{2}$

(B)

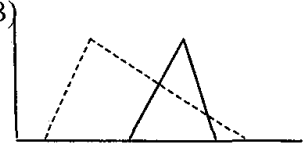

(D)

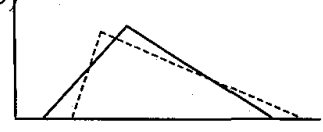

(F)

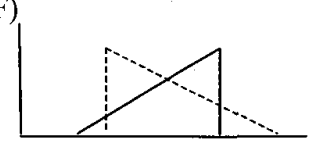

(H)

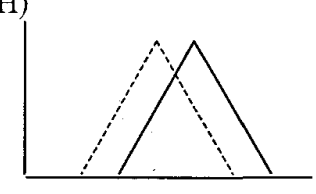

( $)$

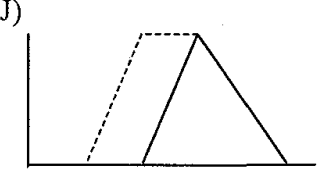

Figure $1 \quad$ Example of representative cases

Adjustments on the indices are made to allow the fuzzy numbers ranked in an ascending order of the index value. Yager's index [59] and Kerre's index [34] are changed by subtracting their index values from 1 and the fuzzy numbers can be ranked in an ascending order of the revised index values. In Kolodziejczyk's indices $R_{i}\left(A_{i}, A_{j}\right)$ [37] is explained as the degree to which $A_{i}$ is not preferred to $A_{j}$ or is dominated by $A_{j}$. With the following changes, $R_{i}^{\prime}\left(A_{i}, A_{j}\right)$ can be interpreted as the degree to which $A_{i}$ is preferred to $A_{j}$ or $A_{i}$ dominate $A_{j}$. Chang's index [9] is multiplied by 2 to ensure that the comparability of the indices. Table 2 shows the computation results.

To conduct the discriminative analysis of these representative approaches in ranking fuzzy numbers, the ranking consistency and ranking effectiveness indices are calculated based on (1) and (2). Tables 3 and 4 present a comparison of these approaches in ranking fuzzy numbers with respect to these two measures.

Not a single approach dominates the other approaches with respect to the two objective performance measures, as shown in Tables 3 and 4 . Their discrimination ability decreases when the fuzzy numbers involved are closer. Except the approach of Lee and $\mathrm{Li}$ [38], all other approaches have problems in separating similar fuzzy numbers. In general, the approaches involving the concept 
of Hamming distance produce better results except that of Yager [60] and Kerre [34].

Table 3 Ranking consistency of typical approaches

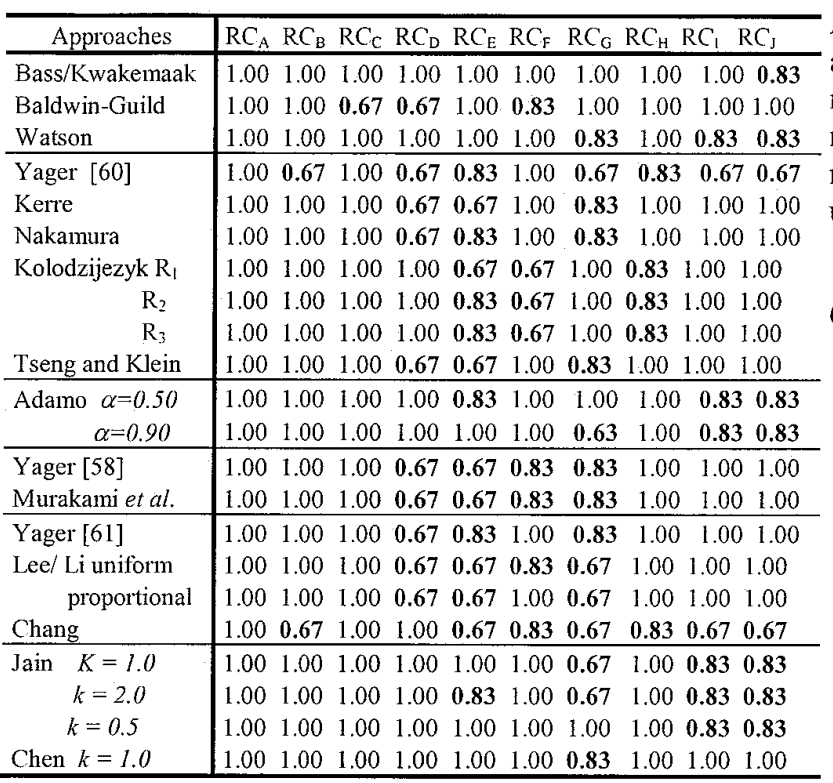

Table 4 Ranking effectiveness of typical approaches

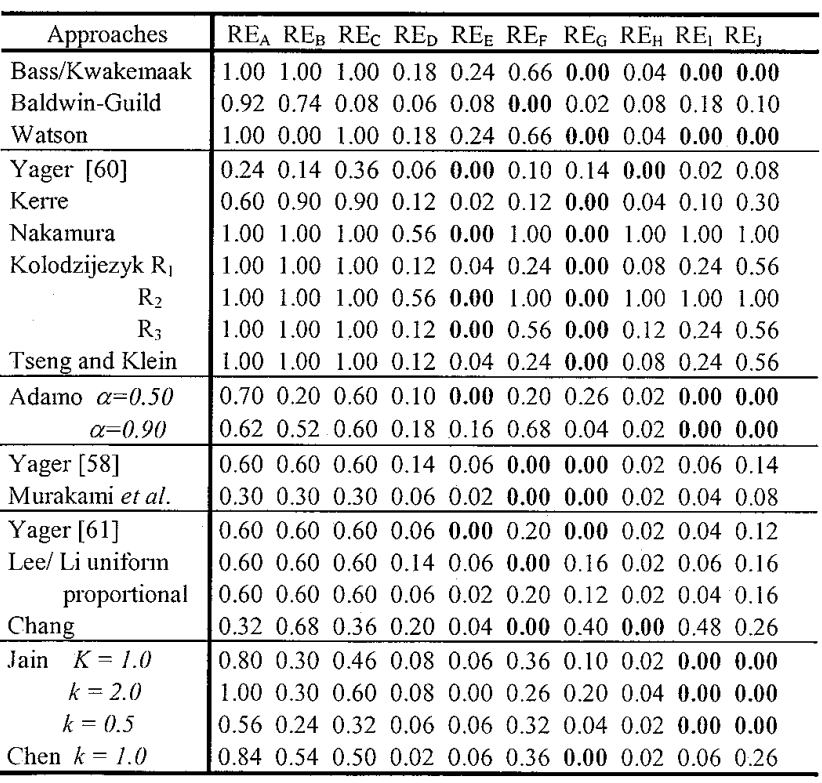

\section{Conclusion}

This paper presents a comprehensive review of existing approaches to comparing and ranking fuzzy numbers. It provides a rational categorization of these approaches and conducts an investigation of the discrimination ability of these approaches in differentiating similar fuzzy numbers. Not a single ranking approach appears to dominate others in terms of its ranking outcomes consistency and discrimination ability. Each approach has its own merit. An ideal ranking approach should be capable of (a) using as much information as possible provided by the fuzzy numbers involved, (b) providing intuitively consistent results to all people, (c) discriminating similar fuzzy numbers effectively, and (d) easy computation with understandable ranking outcomes.

\section{References}

[1] Adamo J.M., Fuzzy Decision Tree. Fuzzy Sets and Systems, Vol. 4, No.3, pp. 207-220, 1980.

[2] Baas S.M. and Kwakernaak H., Rating and Ranking of Multiple-Aspect Alternatives Using Fuzzy Sets. Automatica, Vol. 13, pp. 47-58, 1977.

[3] Baldwin J.F. and Guild N.C.F., Comparison of Fuzzy Sets on the Same Decision Space. Fuzzy Sets and Systems, Vol. 2, pp. 213-231, 1979.

[4] Bonissone P.P. and Efstathiou J., Linguistic Solutions to Fuzzy Decision Problems. TIMS/Studies in the Management Science, Vol. 20, pp. 323-334, 1984.

[5] Bortolan G. (1984). and Degani R., A Review of Some Approaches for Ranking Fuzzy Subsets. Fuzzy Sets and Systems, Vol. 15, pp. 1-19, 1985.

[6] Buckley J.J. and Chanas S., A Fast Approach of Ranking Alternatives Using Fuzzy Numbers (Short Communications). Fuzzy Sets and Systems, Vol. 30, No.3, pp. 337-339, 1989.

[7] Campos L. and Gonzalez, Further Contributions to the Study of the Average Value for Ranking Fuzzy Numbers. International Journal of Approximate Reasoning, Vol. 10, pp. 135-153, 1994.

[8] Carlsson C. and Fuller R., Fuzzy Multiple Criteria Decision Making: Recent Developments. Fuzzy Sets and Systems, Vol. 78, pp. 139-153, 1996.

[9] Chang W., Ranking of Fuzzy Utilities with Triangular Membership Functions. Proceeding of International Conference on Policy and Information Systems, pp. 163272, 1981.

[10] Chen C.T., Extensions of the TOPSIS for Group DecisionMaking under Fuzzy Environment. Fuzzy Sets and Systems, Vol.114, pp. 1-9, 2000.

[11] Chen S.H., Ranking Fuzzy Numbers with Maximizing Set and Minimizing Set. Fuzzy Sets and Systems, Vol. 17, pp. 113-129, 1985.

[12] Chen L.H. and Lu H.W., An Approximate Approach for Ranking Fuzzy Numbers based on Left and Right Dominance. Computers ad Mathematics with applications, Vol. 41, pp. 1589-1602, 2001

[13] Chen S.J. and Hwang C.L., Fuzzy Multiple Attribute Decision Making: Approaches and Applications, SpringerVerlag, New York, 1992.

[14] Chen C.B. and Klein C.M., An Efficient Approach to Solving Fuzzy MADM Problems. Fuzzy Sets and Systems, Vol. 88, pp. 51-67, 1997. 
[15] Choobineh F. and Li H., An Index for Ordering Fuzzy Numbers. Fuzzy Sets and Systems, Vol. 54, pp. 287-294, 1993.

[16] De Campos-Ibanez L. M. and Gonzalez-Munoz A., A Subjective Approach for Ranking Fuzzy Numbers. Fuzzy Sets and Systems, Vol. 29, pp. 145-153, 1989.

[17] Delgado M., Verdegay J.L. and Villa M.A., A Procedure for Ranking Fuzzy numbers Using Fuzzy Relations. Fuzzy Sets and Systems, Vol. 26, No.1, 1988.

[18] Deng H., Multicriteria Analysis with Fuzzy Pairwise Comparison. International Journal of Approximate Reasoning, Vol. 27, pp.215-231, 1999.

[19] Detyniecki M. and Yager R.R., Ranking Fuzzy Numbers Using $\alpha$-Weighted Valuations. International Journal of Uncertainty, Fuzziness and Knowledge-Based Systems, Vol. 8, No. 5, pp.573-591, 2000.

[20] Dubois D. and H. Prade, A Unifying View of Ranking Techniques for Fuzzy Numbers, 1999 IEEE International Fuzzy Systems Conference Proceedings, Seoul, Korea pp. 1328-1333, August 22-25, 1999.

[21] Dubois D. and Prade H., Fuzzy Sets --- A Convenient Fiction for Modeling Vagueness and Possibility. IEEE Transactions on Fuzzy Systems, Vol. 2, pp. 16-21, 1994.

[22] Dubois D. and Prade H., The Mean Value of A Fuzzy Number. Fuzzy Sets and Systems, Vol. 24, pp. 279-300, 1987.

[23] Dubois, D. and Prade, H., Ranking Fuzzy Numbers in the Setting of Possibility Theory. Information Sciences, Vol. 30, pp. 183-224, 1983.

[24] Dubois D. and Prade H., A Unifying View of Comparison Indices in A Fuzzy Set-Theoretic Framework. In: Fuzzy Set and Possibility Theory - Recent Development, R. R. Yager (ed.), Pergamon Press, New York, pp. 3-13, 1982

[25 Efstathiou J. and Tong R., Ranking Fuzzy Sets: A Decision Theoretic approach. IEEE Transactions on Systems, Man, and Cybernetics, Vol. SMC-12, pp. 655-659, 1982.

[26] Efstathiou J. and Tong R., Ranking Fuzzy Sets Using Linguistic Preference Relations. Proceedings of the $10^{\text {th }}$ International Symposium on Multiple-Valued Logic, Northwestern University, Evanston, pp.137-142, 1980.

[27] Freeling A.N.S., Fuzzy Sets and Decision Analysis. IEEE Transactions on Systems, Man, and Cybernetics, Vol. SMC-10, No. 7, pp. $341-354,1980$.

[28] Gonzalez A., A Study of the Ranking Function Approach through Mean Values. Fuzzy Sets and Systems, Vol. 35, pp. $29-41,1990$.

[29] Hwang C.L. and Yoon K., Multiple Attribute Decision Making: Approaches and Applications, Springer-Verlag, New York, 1980.

[30] Hyung L.W., Song Y.S. and Lee K.M., Similarity Measure between Fuzzy Sets and between Elements. Fuzzy Sets and Systems, Vol. 62, pp. 291-293, 1994.

[31] Jain R., Decisionmaking in the Presence of Fuzzy Variables. IEEE Transactions on Systems, Man and Cybernetics, Vol. SMC-6, pp. 698-703, 1976.

[32] Jain R., A Procedure for Multi-Aspect Decision Making Using Fuzzy Sets. International Journal of System Science, Vol. 8, pp. 1-7, 1977.
[33] Kaufmann A. and Gupta M.M., Introduction to Fuzzy Arithmetic, Nostrand Reinhold, New York, 1985.

[34] Kerre E.E., The Use of Fuzzy Set Theory in Electrocardiological Diagnostics. In: M.M. Gupta and E. Sanchez (Eds.), Approximating Reasoning in Decision Analysis, North-Holland, Amsterdam, pp. 277-282, 1982.

[35] Kim K. and Park K.S., Ranking Fuzzy Numbers with Index of Optimism. Fuzzy Sets and Systems, Vol. 35, pp.143-150, 1990.

[36] Klir G.J. and Yuan B., Fuzzy Sets and Fuzzy Logic: Theory and Applications. Prentice Hall, London, 1995.

[37] Kolodziejczyk, W., Orlovsky's Concept of Decision Making with Fuzzy Preference Relation-Further Results. Fuzzy Sets and Systems, Vol. 19, No.1, pp. 11-20, 1986.

[38] Lee E.S. and Li R.J., Comparison of Fuzzy Numbers based on the Probability Measure of Fuzzy Events. Computer and Mathematics with Applications, Vol. 15, pp. 887-896, 1987.

[39] Lee-Kwang H. and Lee J.H., A Approach for Ranking Fuzzy Numbers and Its Application to Decision-Making. IEEE Transactions on Fuzzy Systems, Vol. 7, No. 6, pp. 677-685, 1999.

[40] Li R.J. and Lee E.S., Ranking Fuzzy Numbers - A Comparison, Proc. the North American Fuzzy Information Processing Society Workshop (NAFIPS'87), Purdue University, pp. 169-204, 1987.

[41] Liou T.S. and Wang M.J., Ranking Fuzzy Numbers with Integral Value. Fuzzy Sets and Systems, Vol. 50, pp. 247$255,1992$.

[42] Liu X., Entropy, Distance Measure and Similarity Measure of Fuzzy Sets and Their Relations. Fuzzy Sets and Systems, Vol. 52, pp. 305-318, 1992.

[43] Mabuchi, S., An Approach to the Comparison of Fuzzy Subsets with An $\alpha$-Cut Dependent Index. IEEE Transactions on Systems, Man, and Cybernetics, Vol. SMC-18, pp. 264-272, 1988.

[44] Miller G.A., The Magical Number Seven, Plus or Minus Two: Some Limits on Our Capacity for Processing Information. The Psychological Review, Vol. 63, No.2, pp. $81-97,1956$.

[45] Murakami S., Maeda S. and Imamura S., Fuzzy Decision Analysis on the Development of Centralized Regional Energy Control System, Proceedings of the IFAC Symposium on Fuzzy Information, Knowledge Representation and Decision Analysis, pp. 363-368, 1983.

[46] Nakamura k., Preference Relation between Fuzzy Outcomes. The Working Group on Fuzzy Sets and Systems: Report 5, Tokyo, Japan, 1979.

[47] Nakamura K., Preference Relation on A Set of Fuzzy Utilities as A Basis for Decision Making. Fuzzy Sets and Systems, Vol. 20, pp. 147-162, 1986.

[48] Saaty T.L., Decision Making for Leaders, third edition, RWS Publications, New York, 1995

[49] Sugeno M., Fuzzy Decision-Making Problems. Transactions of Society of Instrument and Control Engineers, Vol. 11, pp. 709-714. 1975.

[50] Tong R.M. and Efstathiou J., A Critical Assessment of Truth Functional Modification and Its Use in Approximate Reasoning (Short Communication). Filzzy Sets and Systems, Vol. 7, No.1, pp. 103-108, 1982. 
[51] Tong R.M. and Bonissone P.P., Linguistic Solutions to Fuzzy Decision Problems. TIMES/Studies in the Management Sciences, Vol. 20, pp. 323-334, 1984.

[52] Tseng T.Y. and Klein C.M., New Algorithm for the Ranking Procedure in Fuzzy Decisionmaking. IEEE Transactions on Systems, Man and Cybernetics, Vol. 19, pp. 1289-1296, 1989.

[53] Tseng T.Y., Klein C.M. and Leonard M.S., A Formalism for Comparing Ranking Procedures. Proceedings of the $7^{\text {th }}$ Annual Meeting of the North American Fuzzy Information Processing Society, pp. 231-235, 1988.

[54] Tsukamoto, Y., Nikiforuk, P.N. and Gupta, M.M., On the Comparison of Fuzzy Sets Using Fuzzy Chopping. In: Control Science and Technology for Progress of Society, Akashi H. (eds.), Pergamon Press, New York, pp. 46-51, 1983.

[55] Wang X. and Kerre E.E., Reasonable Properties for the Ordering of Fuzzy Quantities (I). Fuzzy Sets and Systems, Vol. 118, pp. 375-385, 2000.

[56] Wang X. and Kerre E.E., Reasonable Properties for the Ordering of Fuzzy Quantities (II). Fuzzy Sets and Systems, Vol. 118,pp. 387-405, 2001.

[57] Watson S.R., Weiss J.J., and. Donnell M.L, Fuzzy Decision Analysis. IEEE Transactions on Systems, Man and Cybernetics, Vol. SMC-9, pp. 1-9, 1979.

[58] R.R. Yager, Ranking fuzzy subsets over the unit interva], Proceedings of the CDC (1978), pp.1435-1437, 1978.

[59] R.R. Yager, On choosing between fuzzy subsets. Cybernetics, Vol. 9, pp. 151-154, 1980.
[60] Yager R.R., On A General Class of Fuzzy Connectives. Fuzzy Sets and Systems, Vol. 4, pp. 235-242, 1980.

[61] Yager R.R., A Procedure for Ordering Fuzzy Sets of the Unit Interval. Information Sciences, Vol. 24, pp. 143-161, 1981.

[62] Yeh C.H. and Deng H., A Practical Approach to Fuzzy Utilities Comparison in Fuzzy Multicriteria Analysis. International Journal of Approximate reasoning, Vol. 35, No. 2, pp. 179-194, 2004

[63] Yuan Y., Criteria for Evaluating Fuzzy Ranking Approaches. Fuzzy Sets and Systems, Vol. 44, pp.139-157, 1991.

[64] Zadeh L.A., A Fuzzy-Set-Theoretical Interpretation of Linguistic Hedges. Journal of Cybernetics, Vol. 2, pp. 434, 1972 .

[65] Zadeh L.A., Outline of A New Approach to the Analysis of Complex System and Decision Process. IEEE Transactions on Systems, Man, and Cybernetics, Vol. SMC-2, pp. $28-44,1973$.

[66] Zadeh L.A., The Concept of A Linguistic Variable and its Application to Approximate Reasoning: I, II. Information Sciences, Vol. 8, pp. 199-249; pp. 301-357, 1975.

[67] Zadeh L.A., Fuzzy Sets. Information and Control, Vol. 8, pp. 338-353, 1965.

[68] Zimmermann H.J., Fuzzy Sets, Decision Making, and Expert System, Kluwer, Boston, 1988

Table 2 Computation results of representative cases

\begin{tabular}{|c|c|c|c|c|c|c|c|c|c|c|c|c|c|c|c|c|c|c|c|c|}
\hline \multirow[b]{2}{*}{ Approaches } & \multicolumn{2}{|c|}{ (A) } & \multicolumn{2}{|c|}{ (B) } & \multicolumn{2}{|c|}{ (C) } & \multicolumn{2}{|c|}{ (D) } & \multicolumn{2}{|c|}{ (E) } & \multicolumn{2}{|c|}{$\overline{(F)}$} & \multicolumn{2}{|c|}{$(\mathrm{G})$} & \multicolumn{2}{|c|}{ (H) } & \multicolumn{2}{|c|}{ (I) } & \multicolumn{2}{|l|}{$\overline{(J)}$} \\
\hline & $A_{1}$ & $\mathrm{~A}_{2}$ & $\mathrm{~A}_{1}$ & $\mathrm{~A}_{2}$ & $\mathrm{~A}_{1}$ & $\mathrm{~A}_{2}$ & $\mathrm{~A}_{1}$ & $\mathrm{~A}_{2}$ & $\mathrm{~A}_{1}$ & $\mathrm{~A}_{2}$ & $\mathrm{~A}_{1}$ & $\mathrm{~A}_{2}$ & $\mathrm{~A}_{1}$ & $\mathrm{~A}_{2}$ & $A_{1}$ & $\mathrm{~A}_{2}$ & $\mathrm{~A}_{1}$ & $\mathrm{~A}_{2}$ & $\mathrm{~A}_{1}$ & $\mathrm{~A}_{2}$ \\
\hline Bass-Kwakemaak & 1.00 & 0.00 & 1.00 & 0.50 & 1.00 & 0.50 & 1.00 & 0.91 & 1.00 & 0.88 & 1.00 & 0.67 & 1.00 & 1.00 & 1.00 & 0.98 & 1.00 & 1.00 & 1.00 & 1.00 \\
\hline Baldwin-Guild & .46 & 0.00 & 0.56 & 0.19 & 0.44 & 0.48 & 0.36 & 0.39 & 0.40 & 0.36 & 0.38 & 0.38 & 0.29 & 0.28 & 0.33 & 0.29 & 0.38 & 0.29 & 0.38 & 0.33 \\
\hline Watson & .00 & 0.00 & 0.50 & 0.00 & 0.50 & 0.00 & 0.09 & 0.00 & 0.12 & 0.00 & 0.33 & 0.00 & 0.00 & 0.00 & 0.02 & 0.00 & 0.00 & 0.00 & 0.00 & 0.8 \\
\hline Yager [60] & .59 & 0.47 & 0.59 & 0.66 & 0.74 & 0.56 & 0.67 & 0.69 & 0.64 & 0.64 & 0.67 & 0.62 & 0.59 & 0.66 & 0.56 & 0.56 & 0.64 & 0.65 & 0.64 & \\
\hline Kerre & .00 & 0.70 & 0.99 & 0.54 & 1.00 & 0.55 & 0.89 & 0.95 & 0.95 & 0.96 & 0.93 & 0.87 & 0.90 & 0.90 & 1.00 & 0.98 & 1.00 & 0.95 & 1.00 & 0 \\
\hline Nakamura & .00 & 0.00 & 0.98 & 0.02 & 1.00 & 0.00 & 0.36 & 0.64 & 0.50 & 0.50 & 0.80 & 0.20 & 0.50 & 0.50 & 1.00 & 0.00 & 1.00 & 0.00 & 1.00 & 0 \\
\hline Kolodzijezyk $\mathrm{R}_{1}$ & .00 & 0.00 & 0.87 & 0.13 & 0.87 & 0.13 & 0.47 & 0.53 & 0.49 & 0.51 & 0.56 & 0.44 & 0.50 & 0.50 & 0.52 & 0.48 & 0.56 & 0.44 & 0.64 & 0. \\
\hline $\mathrm{R}_{2}$ & 1.00 & 0.00 & 0.98 & 0.02 & 1.00 & 0.00 & 0.36 & 0.64 & 0.50 & 0.50 & 0.80 & 0.20 & 0.50 & 0.50 & 1.00 & 0.00 & 1.00 & 0.00 & 1.00 & 0. \\
\hline $\mathrm{R}_{3}$ & .00 & 0.00 & 0.90 & 0.10 & 0.90 & 0.10 & 0.47 & 0.53 & 0.50 & 0.50 & 0.64 & 0.36 & 0.50 & 0.50 & 0.53 & 0.47 & 0.56 & 0.44 & 0.64 & \\
\hline Tseng and Klein & 1.00 & 0.00 & 0.87 & 0.13 & 0.87 & 0.13 & 0.47 & 0.53 & 0.49 & 0.51 & 0.56 & 0.44 & 0.50 & 0.50 & 0.52 & 0.48 & 0.56 & 0.44 & 0.64 & 0 \\
\hline Adamo $\alpha=0.50$ & 60 & 0.25 & 0.85 & 0.75 & 0.85 & 0.55 & 0.75 & 0.70 & 0.65 & 0.65 & 0.70 & 0.60 & 0.60 & 0.47 & 0.51 & 0.50 & 0.70 & 0.70 & 0.70 & 0.70 \\
\hline$\alpha=0.90$ & 0.52 & 0.21 & 0.81 & 0.55 & 0.73 & 0.43 & 0.55 & 0.46 & 0.53 & 0.45 & 0.70 & 0.36 & 0.52 & 0.54 & 0.43 & 0.42 & 0.62 & 0.62 & 0.62 & 0.62 \\
\hline Yager [58] & .50 & 0.20 & 0.80 & 0.50 & 0.70 & 0.40 & 0.50 & 0.57 & 0.50 & 0.53 & 0.50 & 0.50 & 0.50 & 0.50 & 0.41 & 0.40 & 0.60 & 0.57 & 0.60 & 0 . \\
\hline Murakamie & 42 & 0.27 & 0.57 & 0.42 & 0.52 & 0.37 & 0.42 & 0.45 & 0.42 & 0.43 & 0.42 & 0.42 & 0.42 & 0.42 & 0.37 & 0.36 & 0.47 & 0.45 & 0.47 & 0. \\
\hline Yager [61] & 50 & 0.20 & 0.80 & 0.50 & 0.70 & 0.40 & 0.50 & 0.53 & 0.50 & 0.50 & 0.55 & 0.45 & 0.50 & 0.50 & 0.50 & 0.49 & 0.51 & 0.49 & 0.53 & 0.47 \\
\hline Lee and Li uniform & 0.50 & 0.20 & 0.80 & 0.50 & 0.70 & 0.40 & 0.50 & 0.57 & 0.50 & 0.53 & 0.50 & 0.50 & 0.08 & 0.16 & 0.41 & 0.40 & 0.60 & 0.57 & 0.60 & 0.53 \\
\hline proportional & 0.50 & 0.20 & 0.80 & 0.50 & 0.70 & 0.40 & 0.50 & 0.53 & 0.10 & 0.11 & 0.55 & 0.45 & 0.06 & 0.12 & 0.41 & 0.40 & 0.60 & 0.58 & 0.60 & 0.52 \\
\hline Chang & 0.20 & 0.04 & 0.16 & 0.50 & 0.42 & 0.24 & 0.50 & 0.40 & 0.30 & 0.32 & 0.30 & 0.30 & 0.20 & 0.40 & 0.16 & 0.16 & 0.24 & 0.48 & 0.24 & 0.37 \\
\hline$K=1.0$ & 0.78 & 0.38 & 0.82 & 0.67 & 0.77 & 0.54 & 0.67 & 0.63 & 0.67 & 0.64 & 0.78 & 0.60 & 0.64 & 0.69 & 0.75 & 0.74 & 0.80 & 0.80 & 0.80 & 0.80 \\
\hline$k=2.0$ & 0.66 & 0.16 & 0.69 & 0.54 & 0.65 & 0.35 & 0.54 & 0.50 & 0.51 & 0.51 & 0.60 & 0.47 & 0.46 & 0.56 & 0.63 & 0.61 & 0.69 & 0.69 & 0.69 & 0.69 \\
\hline$k=0.5$ & 0.87 & 0.59 & 0.90 & 0.78 & 0.86 & 0.70 & 0.78 & 0.75 & 0.79 & 0.76 & 0.88 & 0.72 & 0.78 & 0.80 & 0.85 & 0.84 & 0.88 & 0.88 & 0.88 & 0.88 \\
\hline Chen $k=1.0$ & 0.63 & 0.21 & 0.77 & 0.50 & 0.63 & 0.38 & 0.50 & 0.49 & 0.45 & 0.42 & 0.59 & 0.41 & 0.50 & 0.50 & 0.51 & 0.50 & 0.57 & 0.54 & 0.57 & 0.44 \\
\hline
\end{tabular}

